\title{
Intensive TB Case Finding in Unsafe Settings: Testing an Outreach Peer Education Intervention for Increased TB Case Detection among Displaced Populations and Host Communities in South-Kivu Province, Democratic Republic of Congo
}

\author{
Sylvain Munyanga Mukungo1, Berthollet Bwira Kaboru',3 \\ ${ }^{1}$ Regional School of Public Health, Catholic University of Bukavu, Bukavu, Democratic Republic of Congo \\ ${ }^{2}$ School of Health and Medical Sciences, Örebro University, Örebro, Sweden \\ ${ }^{3}$ Department of Public Health Sciences, Division of Global Health (IHCAR), Karolinska Institutet, Stockholm, \\ Sweden \\ Email: munyangam@yahoo.fr, Berthollet.Kaboru@oru.se,
}

Received 16 September 2014; revised 17 October 2014; accepted 10 November 2014

Copyright (C) 2014 by authors and Scientific Research Publishing Inc.

This work is licensed under the Creative Commons Attribution International License (CC BY).

http://creativecommons.org/licenses/by/4.0/

c) (i) Open Access

\begin{abstract}
Introduction: The Democratic Republic of Congo (DRC) is one of the high-burden TB countries in the world. The most affected provinces were North and South Kivu where displacements of the population favor transmission of infections. Delays in diagnosis are often causes for excessive mortality among TB patients. Aim of the Study: The study aimed to test an intervention designed to increase detection of TB cases in internally displaced persons and their host communities in South Kivu province. Methods: The project used a quasi-experimental method, with prospective data collection every six months. Two peri-urban districts were selected and designated as intervention and control districts respectively. Twenty peer educators were selected among prospective TB suspects who sought care in health facilities. The peer educators were trained and encouraged to actively influence, identify and refer potential TB suspects to health centers. The data on new TB suspects seen and cases diagnosed in both districts were collected and compared over two and a half years period. Results: This pilot study has demonstrated that the intervention has had some positive effects on both the number of persons suspected with TB who were diagnosed using either microscopy or clinical assessment. Even in terms of case detection, the study demonstrated that the number of cases detected in the intervention district was at least twice the number of cases detected in the control district. Conclusion: Nonprofessional educators can influence

How to cite this paper: Mukungo, S.M. and Kaboru, B.B. (2014) Intensive TB Case Finding in Unsafe Settings: Testing an Outreach Peer Education Intervention for Increased TB Case Detection among Displaced Populations and Host Communities in South-Kivu Province, Democratic Republic of Congo. Journal of Tuberculosis Research, 2, 160-167. http://dx.doi.org/10.4236/jtr.2014.24020
\end{abstract}


TB case detection even in unstable settings, but their effectiveness is dependent on the security situation. National TB control programs need to adapt community mobilization strategies to local developments even in unsafe settings.

\section{Keywords}

\section{Tuberculosis, Peer Educators, Conflict-Affected Settings}

\section{Introduction}

The Democratic Republic of the Congo (DRC) is known for successive calamities such as wars, massive displacements, sexual violence, Ebola virus, and aircraft crashes [1] [2]. The burden of ill health is huge in this part of the world. Wars in DRC have had unbearable consequences for the population. More than 6 million persons have died from 1996, which makes the Congo war as devastating as the holocaust [3]. According to estimates, 45,000 deaths occur every year in Congo due to the humanitarian situation resulting from the many years' crisis of neglect of the poor health services [4]. Most of these deaths are caused by preventable and treatable conditions. Malaria, respiratory infections, including tuberculosis (TB) and maternal and neonatal complications are the main causes behind the excessive mortalities in DRC [5] [6].

Presently, DRC exhibits all characteristics of a fragile state. The country's situation is not only of concern for its impoverished people but also for the international community in that stagnation in such a strategic country in the region hinders progress in achieving Millennium Development Goals (MDGs). The High Level Forum of the African leaders in Abuja, Nigeria in 2005 recognized the issue of fragile states in undermining attainment of progress of such countries' health and non-health-related MDGs [7].

One of the most affected provinces in DRC is the South Kivu province where migration and forced populations' movements in all directions have been persistent. TB transmission has been facilitated by crowded living conditions and lack of treatment. Other conditions of vulnerability, malnourishment and weakened immune system are factors that favor development from TB infection to active disease [8]. An unpublished study on delay to diagnosis conducted in Bukavu general hospital has shown that half of the patients were displaced from war and faced with huge problem to access to TB diagnosis due to lack of income. The same study showed that the level of awareness of TB was low and there was inadequate training of health workers (Byamungu and Kashongwe: personal communication, 15 November 2013). The DRC TB and leprosy control program has been trying to find ways to sustain the control program in a destroyed health system; in spite of this, innovative alternatives remain welcomed by the policy makers [9].

Effective TB case detection and treatment are important in fragile states, conflict and post-conflict settings. TB treatment and control are possible in a conflict setting and the World Health Organization (WHO) targets for cure have been found to be achievable. The factors associated with the success of the program in these settings have been said to be strong local community support, the selection of outreach workers from each ethnic group allowing access to all areas and patients, the use of directly observed therapy three times a week instead of daily in the interest of increased safety, and the limiting of distances travelled by both outreach workers and patients [10].

The DRC in general and South Kivu in particular have been affected by war since 1992, causing displacements of the population. Despite the state of war, the National Tuberculosis Control Program (NTP) was able to pursue efforts to control the disease within the framework of devastated health care system. Settings with chronic instability like in Eastern DRC are complex. People are almost continuously on the move, the most vulnerable populations are not always located in "organized and serviced: camps but scattered within a certain perimeter around main villages or even hidden. A study conducted in the General Referral Provincial Hospital of Bukavu showed that half of the patients were people who fled and who had no access to diagnosis and treatment of TB due to lack of revenue. The same study also showed that the level of knowledge of TB was low and that health personnel had no proper training in the field (Byamungu and Kashongwe: personal communication, 15 November 2013).

In such settings, innovative approaches need to be designed, tested and evaluated. This project focused on enhancing prevention of TB, detection of infected cases, care and post-treatment monitoring of TB in a population at risk in the province of South Kivu, using a peer educators' strategy in a highly unstable and violent environment. 


\section{Aim of the Study}

To test the efficacy of a peer outreach strategy to increase TB case detection among internally displaced persons (IDPs) and host communities in the peri-urban districts of the Bukavu region.

\section{Methods}

\subsection{Design}

The project adopted a quasi-experimental approach, with an intervention and a control district, and progressive measurements of the key outcome indicator (the number of new cases detected) in the respective districts.

\subsection{Settings}

The study was conducted in two health districts surrounding the city of Bukavu. The Provincial Coordination of the National Program for TB control (NTP) in South Kivu in Bukavu was partner in the implementation of the research. Normally, health districts of the province conduct anti-TB activities on regular basis using trained, permanent and well-established community members who sensitize their communities on TB prevention and care. Treatment support and prevention activities are organized in settings such as in schools, churches, colleges etc. Beyond this conventional community mobilization policy, this project wanted to focus on internally displaced people, mobile and intensively trained to conduct not only door to door, neighborhood to neighborhood sensitization but also visit remote places, inviting even unsettled groups of population to seek care for TB. It was expected that relying on peer educators who themselves had experienced symptoms suggestive of TB and were IDPs characterized by high mobility would allow them to reach the most hard to reach population (IDPs and host communities). They were expected to sensitize new suspects thus leading to detection of new cases.

After analysis and comparison of baseline health districts data by the research team, and after discussions between the team and the national tuberculosis control team, it was agreed that the Kadutu health district be taken as intervention and Miti/Murhesa district as the control one. Below is some factual information about the two districts at baseline. Both districts are relatively easy to access both for the research team and the regional TB control program coordination (about 7 to $30 \mathrm{~km}$ outside of the Bukavu city center). Kadutu and Miti/Murhesa health districts cater for a permanent population of about 250,000 inhabitants per districts, excluding groups of displaced persons whose number can reach up to 100,000 per district at times. Kadutu is endowed with four secondary level hospitals whereas Miti/Murhera has three, beyond a network of health centers that conduct diagnosis and provides treatment for TB. As to human resources, Kadutu health district has a total of 425 staff, whereas Miti/Murhesa has about 306, all categories included.

\subsection{Hypothesis}

We anticipated a stronger increase in case detection in the intervention district as compared to the control one, as a result of peer educators' intensive activity in their communities and among the IDPs and host communities.

\subsection{The Intervention: Selection, Training and Supervision of Peer Educators}

Inclusion criteria for potential future peer educators were:

- Having come with symptoms that required undergoing TB detection examinations in the health facility;

- Being between 14 - 45 years old. Older patients were excluded because of the mobility requirement;

- Residing in the concerned health districts either as local community member or an internally displaced person;

- Having never participated in any other study or training activity on TB;

- Giving an informed consent by signing an appropriate declaration.

Twenty prospective patients were selected by simple random method to be peer educators. They provided biological samples of sputum and underwent radiographic examination of the lungs.

Capacity building of peer educators involved in the administration of eight biweekly sessions of 90 minutes.

The sessions for capacity building of peer educators were organized in small groups of eight to 12 people. The content of the training (see Table 1) was based on the guidelines for capacity building of peer educators as recommended by the SHIELD project with the oretical principles and exercises and role play [11]. 
Table 1. Topics covered during peer education training sessions.

\begin{tabular}{|c|c|}
\hline Sessions & Topics \\
\hline Session 1 & The concept of peer educator and their role in promoting behavior change \\
\hline Session 2 & Tuberculosis prevention, risk factors, management and monitoring \\
\hline Session 3 & Communication skills in prevention, management and monitoring of TB \\
\hline Session 4 & Techniques, tips, messages refusal to catch/lead to the spread of TB \\
\hline Session 5 & The concept of behavior change \\
\hline Session 6 & Obstacles related to the personality of the peer educator \\
\hline Session 7 & A testimony of a case of manifest success and failure in the fight against TB in the province \\
\hline Session 8 & $\begin{array}{l}\text { A synthesis and evaluation of the previous } 7 \text { meetings } \\
\text { Working plans/timing diagrams of peer educators activities }\end{array}$ \\
\hline
\end{tabular}

\subsection{Data Collection}

Every six months for a period of two and a half years, the project collected the information from health facilities in both the intervention and control districts regarding the number of patients suspected to be infected with TB who came to seek care and the number of TB cases diagnosed through laboratory test and through clinical assessments.

\subsection{Data Analysis}

The research team was interested in describing and observing the general trends that the data indicated. The data was therefore analyzed using descriptive statistics, notably frequencies and percentages and graphs. No significance tests were run because of the pilot nature of the data which was too limited: small sample size and too few measurement occasions.

\section{Results}

\subsection{TB Suspects Who Underwent Microscopy Test}

As an impact of the peer educators' mobilization work, the flow of patients who came to health facilities with symptoms suggestive of TB was analyzed. Figure 1 below shows that the number of patients presenting with symptoms to the facilities in the intervention district increased by threefold between the first and the fifth semester as compared with a twofold increase in the control district. The robust growth in the number of TB suspects between semester 1 and 2 in the intervention district went suddenly down in the third semester following deterioration of the political situation in the region (see Figure 1). That trend was reflected in the rest of figures.

\subsection{Confirmed Cases after Microscopy Test}

The number of cases diagnosed following microscopy test has increased significantly in the intervention district compared with the control district (see Figure 2).

\subsection{Suspects Tested Using Methods Other than Microscopy}

The number of TB suspects who visited health facilities and were assessed for TB using other clinical methods indicated also that the intervention district experienced a higher number of visits compared with the control group (see Figure 3).

\subsection{Cases Detected Using Clinical Assessments}

The cases detected using clinical assessment indicated that slightly more cases were diagnosed in the intervention district as compared with the control district (see Figure 4). 


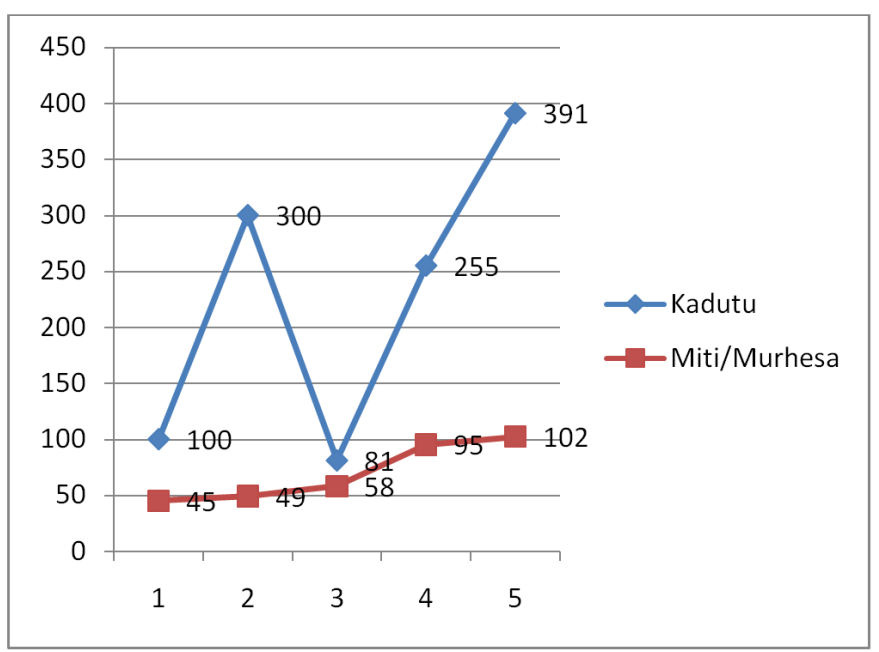

Figure 1. TB suspects who took microscopy test. The $\mathrm{X}$-axis indicates the time-points (semester $1,2 \ldots$ ) and the $\mathrm{Y}$-axis represents the number of TB suspects subjected to microscopy test in the health facilities.

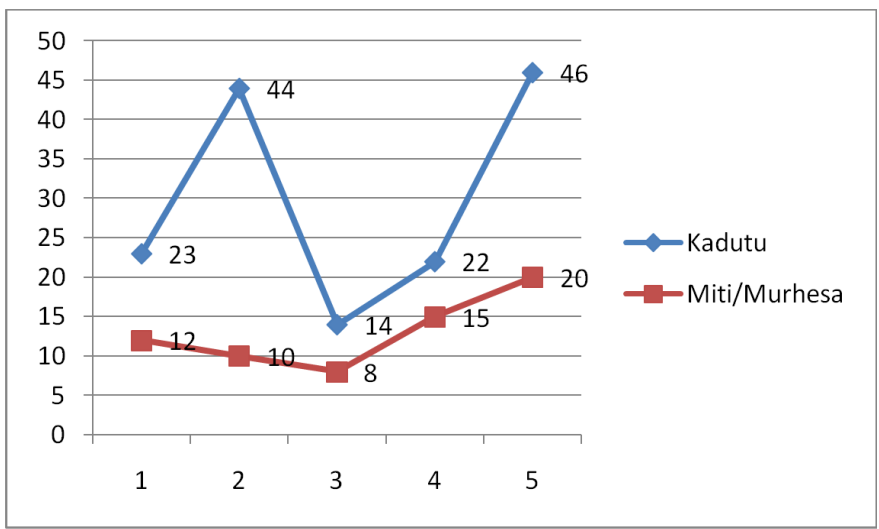

Figure 2. Confirmed TB cased after microscopy test. The X-axis indicates the time-points (semester $1,2 \ldots$ ) and the $\mathrm{Y}$-axis represents the number of TB cases diagnosed by microscopy.

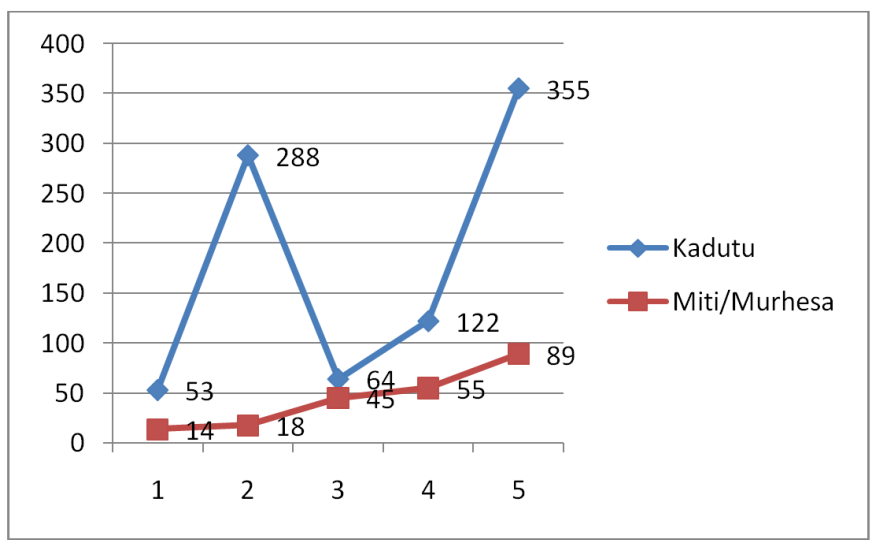

Figure 3. TB suspects assessed using clinical methods. The X-axis indicates the time-points (semester $1,2 \ldots$ ) and the Y-axis represents the number of $\mathrm{TB}$ suspects assessed in the health facilities using clinical assessment methods. 


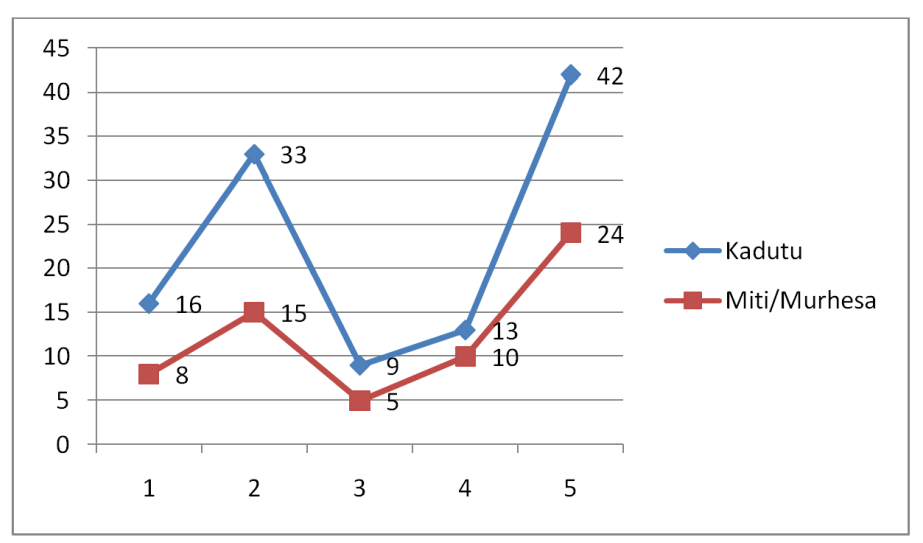

Figure 4. TB cases diagnosed using clinical assessments. The $\mathrm{X}$-axis indicates the time-points (semester $1,2 \ldots$ ) and the $\mathrm{Y}$-axis represents the number of TB cases diagnosed using other clinical methods.

\section{Discussion}

The use of peer educators in intensive TB case finding is still a rare strategy in Africa. Elsewhere however, reports of peer educators' projects in England showed an increased in TB case detection [12], improved knowledge and practice pertinent to TB prevention in China [13] and increased TB treatment completion rate among students in USA [14]. These examples seem to indicate that peer-led programs for TB control have been in stable and somewhat institutionalized settings.

The present explorative study is innovative in that it attempted to use this approach in a complex and unpredictable environment where health systems and social institutions are vulnerable. There is a need for innovative strategies to reinforce TB case finding in Congolese remote and conflict-affected settings. Several interventions have been attempted to reverse the poor performance of TB control programs, including social mobilization and compensation to service providers. In interventions where financial compensation based on performance were offered to service providers (covering for instance consultation fees and hospital admission costs), the rate of TB case detection improved by $4.5 \%$ between 2005 and 2008 against $14.5 \%$ in the settings where social interventions were included, covering active case finding and psychological support led by a community organization [15]. No peer education program was reported among those interventions. This pilot exercise should therefore be seen as an effort to identify alternatives to passive TB case finding in a highly volatile and risky environment.

Comparing general trends in terms of the number of TB suspects who were channeled to health facilities and the number of those who actually diagnosed, the increase in the intervention district appeared more robust that in the control district. Even if the trends were also somewhat positive in the control district, the growth was more stringent in the intervention group. For instance, the number of people who underwent laboratory examination multiplied by three in the intervention district but only doubled in the control district. For TB suspects who were assessed using clinical methods, their evolution indicated a sevenfold increase.

This study relied on peer education by people who delivered interpersonal communication on TB and on the advantages of early diagnosis and proper adherence to TB treatment. An interesting concept of these educators is that they were all presumptive TB patients, i.e. persons who presented to the clinics with symptoms suggestive of TB infection but who were tested negative.

This pilot intervention was unfortunately affected by an upsurge of hostilities between the Congolese government army and a rebellion that emerged in the region during the second half of the project. The rebellion group was called M-23 became very active in the region during 2012, causing massive population movements. The graphs in control and intervention districts show how the detection figures were severely affected. One would argue that these events affected the efficacy of the intervention as a whole. Indeed, the decrease in the numbers of TB suspects who came in the second half in both districts was so deep that the project did not recover to regain the initial impetus, even if the positive impact did resume. In other words, the impact was there, but its strength was moderated by the poor security situation resulting from intensified fighting and population displacements. 
This study has had significant impact in informing clinicians, policy makers and academicians on the importance of investing in lay people to conduct community-based strategies to respond to pressing community health problems, such as TB diagnosis, care and support in difficult contexts. What this project has demonstrated is that nonprofessional peer educators can have an impact in improving TB case detection. This difference can be the result of the regularity and intensity of the supervision as well as the mobility of the mobile peer educators as compared with the ordinary voluntary community activists.

Furthermore, given that there is a time gap between detection and treatment, additional data related to treatment outcomes on both districts will be required in order to find out whether the apparent differences between the intervention and the control districts in relation to detection data persists even after analysis of TB treatment outcome data, i.e. treatment success rate, treatment adherence, treatment failure rates, defaulter rates etc.

\section{Conclusions and Policy Implications}

Nonprofessional educators can influence TB case detection even in unstable settings, but their effectiveness is dependent on the security situation. National TB control programs need to adapt community mobilization strategies to local developments in the concerned settings.

In term of policy recommendations, this study suggests that policy makers should consider the followings:

- Adoption by the NTP of an active approach instead of a passive one, in order to address TB in fragile and unsafe communities. However, in order for the strategy to increase TB case detection, it will require more efforts and resources in terms of supervision and coordination with health facilities as compared to conventional community mobilization strategies that are more passive.

- The NTP would benefit if they could contract out to local organizations tasks such as follow-up activities, refresher training of peer educators or field data collection. Such local organizations should be present in the communities to facilitate easy access to the populations.

- Cost-effectiveness studies are needed to assess whether it is really worthwhile to spend more for the additional cases detected. Such studies would be appropriate after replication of the strategy in another setting and prior to any scaling up of the strategy.

\section{Acknowledgements}

The authors are grateful to the Swedish Agency for Civil Contingencies (MSB) for funding this study (Grant Number 2010-7872) through a special funding mechanism with the Swedish International Development Agency (Sida). Thanks to Dr. Dieudonné Kalumuna, the Provincial Coordinator for the National TB Control Program in South Kivu for supporting the project throughout and Dr. Nana Munyanga, Projects' Officer at the UCB Bukavu for coordinating all field work. Thanks to the peer educators for their commitment to the project.

\section{References}

[1] Harvard Humanitarian Initiative (2010) "Now the World Is without Me”: An Investigation of Sexual Violence in Eastern Democratic Republic of Congo. A Report by the Harvard Humanitarian Initiative with Support from Oxfam America, Harvard Humanitarian Initiative \& Oxfam International, Boston.

[2] Grard, G., Biek, R., Tamfum, J.J., Fair, J., Wolfe, N., Formenty, P., Paweska, J. and Leroy, E. (2004) Emergence of Divergent Zaire Ebola virus Strains in Democratic Republic of the Congo in 2007 and 2008. Journal of Infectious Diseases, 11, S776-S784. http://doi.org/10.1093/infdis/jir364

[3] Coghlan, B., Brennan, R.J., Ngoy, P., Dofara, D., Otto, B., Clements, M. and Stewart, T. (2006) Mortality in the Democratic Republic of Congo: A Nationwide Survey. The Lancet, 367, 44-51. http://dx.doi.org/10.1016/S0140-6736(06)67923-3

[4] Zarocostas, J. (2009) Some 45,000 People Die Each Month in Congo as Result of Collapsed Health Service, Says UN Official. BMJ, 338, b2652.

[5] Van Herp, M., Parque, V., Rackley, E. and Ford, N. (2003) Mortality, Violence and Lack of Access to Healthcare in the Democratic Republic of Congo. Disasters, 27, 141-153. http://dx.doi.org/10.1111/1467-7717.00225

[6] Henegar, C., Behets, F., Vanden Driessche, K., Tabala, M., Bahati, E., Bola, V. and Van Rie, A. (2012) Mortality among Tuberculosis Patients in the Democratic Republic of Congo. International Journal Tuberculosis and Lung Diseases, 16, 1199-1204. ttp://dx.doi.org/10.5588/ijtld.11.0613

[7] High-Level Forum on Health MDGs (2010) Health in Fragile States: An Overview Note. Paris, 14-15 November, ac- 
cessed on 05 July 2010. http://www.hlfhealthmdgs.org/Documents/HealthFragileStates.pdf

[8] Rieder, H. (1999) Epidemiologic Basis of Tuberculosis Control. International Union against Tuberculosis and Lung Disease, Paris.

[9] Byamungu, D.C. and Ogbeiwi, O.I. (2003) Integrating Leprosy Control into General Health Service in a War Situation: The Level after 5 Years in Eastern Congo. Leprosy Review, 74, 68-78.

[10] Rodger, A.J., Toole, M., Lalnuntluangi, B., Muana, V. and Deutschmann, P. (2002) DOTS-Based Tuberculosis Treatment and Control during Civil Conflict and an HIV Epidemic, Churachandpur District, India. Bulletin of the World Health Organization, 80, 451-456.

[11] Self-Help in Eliminating Life-Threatening Diseases (2011) The Self-Help in Eliminating Life-threatening Diseases (SHIELD): A Start Kit. Center for Diseases Control (CDC). Accessed 10 November 2013. http://effectiveinterventions.org/en/HighImpactPrevention/Interventions/SHIELD.aspX

[12] Croft, L.A., Hayward, A.C. and Story, A. (2013) Tuberculosis Peer Educators: Personal Experiences of Working with Socially Excluded Communities in London. International Journal of Tuberculosis and Lung Disease, 17, 36-40. http://dx.doi.org/10.5588/ijtld.13.0309

[13] Liu, Q., Liu, L., Vu, H., Liu, X., Tang, S. and Wang, H. (2013) Comparison between Peer-Led and Teacher-Led Education in Tuberculosis Prevention in Rural Middle Schools in Chongqing, China. Asia-Pacific Journal of Public Health, 4, 1-11. http://doi.org/10.1177/1010539513498767

[14] McCue, M. and Afifi, L.A. (1996) Using Peer Helpers for Tuberculosis Prevention. Journal of American College Health, 44, 173-176. http://dx.doi.org/10.1080/07448481.1996.9937525

[15] Management Sciences for Health (MSH) (2008) Democratic Republic of Congo (DRC) Primary Health Care Project in West/Central Congo: Assessment Report. Accessed on 15 August 2014. http://pdf.usaid.gov/pdf_docs/PNADS456.pdf 
Scientific Research Publishing (SCIRP) is one of the largest Open Access journal publishers. It is currently publishing more than 200 open access, online, peer-reviewed journals covering a wide range of academic disciplines. SCIRP serves the worldwide academic communities and contributes to the progress and application of science with its publication.

Other selected journals from SCIRP are listed as below. Submit your manuscript to us via either submit@scirp.org or Online Submission Portal.
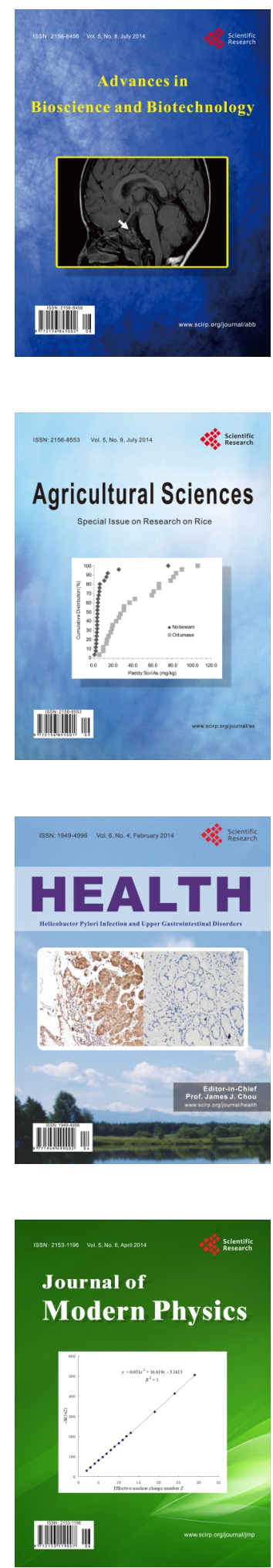
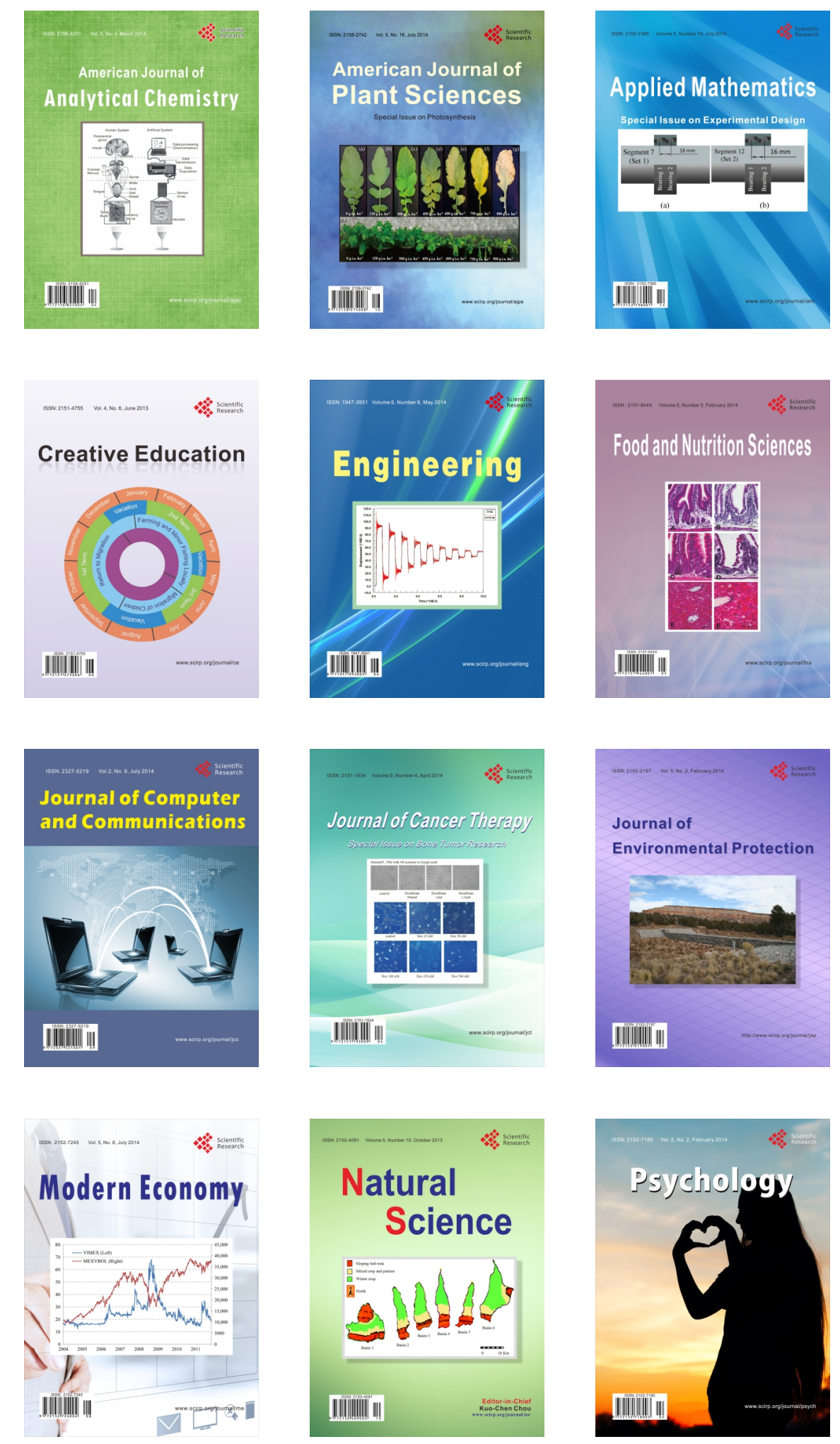